DOSSIÊ TEMÁTICO: Política de Educação Superior

dO1 https://doi.org/10.22481/praxisedu.v16i41.7257

\title{
UNIVERSIDADES ESTADUAIS BRASILEIRAS: DIVERSIDADE ACADÊMICA, CLASSIFICAÇÕES INSTITUCIONAIS E NORMATIVAS
}

\author{
BRAZILIAN STATE UNIVERSITIES: ACADEMIC DIVERSITY, INSTITUTIONAL AND \\ NORMATIVE CLASSIFICATIONS
}

\begin{abstract}
UNIVERSIDADES ESTATALES DE BRASIL: DIVERSIDAD ACADÉMICA, CLASIFICACIONES INSTITUCIONALES Y NORMATIVAS
\end{abstract}

Renata Ramos da Silva Carvalho

Universidade Estadual de Goiás - Brasil

Nelson Cardoso Amaral

Universidade Federal de Goiás - Brasil

\begin{abstract}
Resumo: O propósito deste estudo é analisar e discutir o perfil institucional e acadêmico das Universidades estaduais brasileiras (UEs) mediante discussão teórica e análise de dados, tendo em vista critérios de classificação institucional e normativos para universidades. Além da introdução, o estudo está estruturado em três seções que se articulam para as análises e discussões: a) apreciação do perfil institucional e acadêmico das UEs segundo a abordagem proposta por Steiner (2006); b) apreciação do perfil institucional e acadêmico das UEs segundo uma das propostas classificatórias apresentadas por Nunes, Carvalho e Albrecht (2009); c) análise das características institucionais das UEs do país, tendo em vista os parâmetros estabelecidos pela Resolução n. ${ }^{\circ}$ 03/2010 do Conselho Nacional de Educação, que define os critérios mínimos para que uma Instituição de Educação Superior (IES) seja credenciada/recredenciada como universidade. Os critérios definidos por essa resolução contemplam os previstos na Constituição Federal de 1988 (CF de 1988) e na Lei de Diretrizes e Bases da Educação Nacional (LDB/1996). Do ponto de vista metodológico, o estudo se caracteriza como documental e bibliográfico e possui como fundamento o exame de documentos e de produção intelectual pertinente ao tema, além da apreciação e tratamento de dados disponíveis nos sites do Instituto Nacional de Estudos e Pesquisas Educacionais Anísio Teixeira (Inep) e da Coordenação de Aperfeiçoamento de Pessoal de Nível Superior (Capes). Conclui-se que em relação à análise das características acadêmicas das UEs, segundo critérios de classificação institucional e normativo, foi possível observar a existência de consideráveis assimetrias entre as UEs do país.
\end{abstract}

Palavras-chave: Universidades estaduais, diversidade acadêmica, classificação institucional.

Abstract: The purpose of this study is to analyze and discuss the institutional and academic profile of the Brazilian State Universities (UEs) upon theoretical discussion and data analysis, considering the institutional and normative classification criteria for universities. In addition to the introduction, this study is divided into three sections that articulate between each other in the analysis and discussions: a) 
evaluation of the institutional and academic profile of the Estate Universities (UEs) according to the approach proposed by Steiner (2006); b) evaluation of the institutional and academic profile of the UEs according to one of the classification proposals presented by Nunes, Carvalho and Albrecht (2009); c) analysis of the institutional characteristics of the UEs of the country, considering the parameters established by Resolution No. 03/2010 of the National Council of Education, which defines the minimum criteria for a Higher Education Institution (IES) to be accredited/re-accredited as a university. The criteria defined by this resolution include those provided in the Federal Constitution of 1988 (CF 1988) and in the Law of Directives and Bases of National Education (LDB/1996). From a methodological aspect, the study is characterized as documentary and bibliographic. It is based on the examination of documents and intellectual production pertinent to the theme, as well as the evaluation and processing of data available on the websites of the National Institute for Educational Studies and Research Anísio Teixeira (Inep) and the Coordination for the Improvement of Higher Education Personnel (Capes). It is concluded that regarding the analysis of the academic characteristics of the UEs and according to the institutional and normative classification criteria, it was possible to observe the existence of considerable asymmetries between the UEs of the country.

Keywords: State universities; academic diversity; classification.

Resumen: El objetivo de este estudio es analizar y discutir el perfil institucional y académico de las universidades estatales brasileñas (UEs) a través de la discusión teórica y el análisis de datos, considerando criterios de clasificación institucionales y normativos para las universidades. Además de la introducción, el estudio está estructurado en tres secciones que se articulan para análisis y discusión: a) evaluación del perfil institucional y académico de las UEs de acurdo con el enfoque propuesto por Steiner (2006); b) evaluación del perfil institucional y académico de las UEs de acuerdo con una de las propuestas de clasificación presentadas por Nunes, Carvalho y Albrecht (2009); c) análisis de las características institucionales de las UE del país, en vistas de los parámetros establecidos por la Resolución No. 03/2010 del Consejo Nacional de Educación, que define los criterios mínimos para que una Institución de Educación Superior (IES) sea acreditada/re-acreditada como universidad. Los criterios definidos por esta resolución abarcan los previstos en la Constitución Federal de 1988 (CF 1988) y en la Ley de Directrices y Bases de la Educación Nacional (LDB/1996). Desde el punto de vista metodológico, el estudio se caracteriza como documental y bibliográfico y tiene como fundamento una revisión de documentos y producciones intelectuales relevantes para el tema, además de la evaluación y el procesamiento de los datos disponibles en los sitios web del Instituto Nacional de Estudios e Investigaciones Educativas Anísio Teixeira (Inep) y de la Coordinación de Perfeccionamiento de Personal de Nivel Superior (Capes). Se puede concluir que, con relación al análisis de las características académicas de las UEs, según criterios de clasificación institucional y normativa, fue posible observar la existencia de asimetrías considerables entre las UE del país.

Palabras clave: Universidades estatales; diversidad académica; clasificación.

\section{Introdução}

Em estudos realizados no início da década de 1990, Cunha (1992) já ressaltava que o exame do panorama das IES que possuíam o status jurídico de universidade, revelava um cenário de desigualdade e diferenciação entre essas instituições. Segundo ele, das 95 universidades que existiam, somente de "10 a 15 seriam universidades efetivas, que produzem 
e disseminam ciência, cultura e tecnologia" (CUNHA, 1992, p.1), mesmo havendo diferenças entre elas. Ressaltou ainda que

[...] umas 30 a 40 são universidades potenciais, com poucos e fracos setores maduros, envolvidos e freados por uma maioria arcaica, com quem travam uma disputa mais do que hegemônica, de vida e morte; e as outras nada mais são do que universidades nominais, isto é, meras instituições de ensino superior (raramente de boa qualidade), que adquiriram esse status pela mobilização de recursos políticos incidentes diretamente sobre o Estado (no caso das públicas) ou pela intermediação dos conselhos de educação (no caso das privadas). (Ibid., p. 1)

Embora esse autor tenha feito essa crítica quanto à desigualdade e diferenciação entre as universidades do país e tenha caracterizado parte desse conjunto como universidades potenciais e universidades nominais, ele não estabeleceu os critérios a serem considerados para cada uma dessas classificações. Perante a necessidade de se ter estudos que tenham definido critérios objetivos que possibilitem a análise das diferenças acadêmicas existentes no conjunto das 38 UEs do país, este estudo utilizar-se-á de duas propostas que estabeleceram critérios para análise dessa diferenciação por meio de categorias classificatórias.

Porém, é preciso ressaltar que a utilização dessas duas propostas de classificação institucional não possui o objetivo de estabelecer uma hierarquia no conjunto das UEs brasileiras e que os dados obtidos por meio dessas análises precisam ser contextualizados e problematizados, ou seja, precisam ser relativizados e não podem ser considerados como absolutos para se estabelecer conclusões sobre o conjunto das UEs ou uma UE específica. Todavia, a apreciação do conjunto das UEs, por meio desses critérios, contribui para analisar essas IES a partir de suas características institucionais, que, por sua vez, também contribui para revelar consideráveis elementos das assimetrias desse conjunto.

A primeira metodologia de classificação institucional a ser utilizada neste estudo é a de Steiner (2006) e, a segunda, é uma das propostas classificatórias apresentadas por Nunes, Carvalho e Albrecht (2009). Além de analisar as características institucionais das 38 UEs do país, tendo em vista os critérios desses dois modelos, será realizado também o levantamento dos dados dessas instituições segundo os critérios estabelecidos pela Resolução n. ${ }^{\circ}$ 03/2010 do Conselho Nacional de Educação, que define os critérios mínimos para que uma IES do Sistema Federal de Educação Superior seja credenciada/recredenciada como universidade. Os critérios mínimos definidos por essa resolução contemplam os previstos na CF de 1988 e LDB/1996.

As UEs, criadas e mantidas pelos estados da federação são subordinadas ao Sistema Estadual de Educação de seus estados, com exceção para a oferta de educação a distância e a 
pós-graduação stricto sensu. Os estados possuem a competência legal para desenvolverem seus processos regulatórios de autorização, reconhecimento, credenciamento e os de avaliação dessas instituições. Essa especificidade na legislação quanto às UEs corrobora para que elas se constituam como um segmento heterogêneo com particularidades próprias, pois possuem mantenedores diferentes com regulamentações próprias e distintas. O quadro 1 apresenta a relação nominal das $38^{1}$ UEs brasileiras existentes no país, tendo como referência os dados do Inep disponíveis no Censo da Educação Superior de 2015 e o ano de criação de cada uma delas como universidade.

Quadro 1 - Relação e distribuição das UEs brasileiras, por região e estado da federação, ano de criação e quantidade de campus/unidades universitárias

\begin{tabular}{|c|c|c|}
\hline Estado & Instituições & $\begin{array}{l}\text { Ano de } \\
\text { criaçãa } 0^{2}\end{array}$ \\
\hline \multicolumn{3}{|c|}{ Norte } \\
\hline RR & Universidade Estadual de Roraima - UERR & 2005 \\
\hline TO & Fundação Universidade do Tocantins - Unitins & 1996 \\
\hline $\mathrm{AP}$ & Universidade do Estado do Amapá - Ueap & 2006 \\
\hline AM & Universidade do Estado do Amazonas - UEA & 2001 \\
\hline PA & Universidade do Estado do Pará - Uepa & 1993 \\
\hline \multicolumn{3}{|c|}{ Nordeste } \\
\hline PB & Universidade Estadual da Paraíba - UEPB & 1987 \\
\hline BA & $\begin{array}{l}\text { Universidade Estadual de Feira de Santana - UEFS } \\
\text { Universidade Estadual do Sudeste da Bahia - Uesb } \\
\text { Universidade Estadual de Santa Cruz - Uesc } \\
\text { Universidade do Estado da Bahia - Uneb } \\
\end{array}$ & \begin{tabular}{|l|}
1976 \\
1987 \\
1991 \\
1983 \\
\end{tabular} \\
\hline PI & Universidade Estadual do Piauí - Uespi & 1988 \\
\hline MA & Universidade Estadual do Maranhão - Uema & 1981 \\
\hline $\mathrm{PE}$ & Universidade de Pernambuco - UPE & 1990 \\
\hline $\mathrm{CE}$ & $\begin{array}{l}\text { Universidade Estadual do Ceará - Uece } \\
\text { Universidade Estadual do Cariri - Urca } \\
\text { Universidade Estadual Vale do Acaraú - UVA }\end{array}$ & $\begin{array}{l}1975 \\
1986 \\
1984 \\
\end{array}$ \\
\hline $\mathrm{AL}$ & $\begin{array}{l}\text { Universidade Estadual de Alagoas - Uneal } \\
\text { Universidade de Ciências da Saúde de Alagoas - Uncisal }\end{array}$ & $\begin{array}{l}1995 \\
2005 \\
\end{array}$ \\
\hline RN & Universidade do Estado do Rio Grande do Norte - Uern & 1987 \\
\hline \multicolumn{3}{|c|}{ Sudeste } \\
\hline RJ & $\begin{array}{l}\text { Universidade do Estado do Rio de Janeiro - Uerj } \\
\text { Universidade Est. do Norte Fluminense Darcy Ribeiro - Uenf }\end{array}$ & $\begin{array}{l}1975 \\
1991 \\
\end{array}$ \\
\hline MG & $\begin{array}{l}\text { Universidade do Estado de Minas Gerais - UEMG } \\
\text { Universidade Estadual de Montes Claros - Unimontes }\end{array}$ & $\begin{array}{l}1994 \\
1994\end{array}$ \\
\hline SP & Universidade de São Paulo - USP & 1934 \\
\hline
\end{tabular}

${ }^{1}$ O Censo da Educação Superior de 2016 apresentou uma alteração quanto ao quantitativo de UEs, indicando a existência de 39. Detalhando essa informação, essa alteração refere-se ao estado de São Paulo, que passou a constar 4. A Univesp foi criada em 2012 como uma fundação e depois credenciada como universidade. Para este estudo, serão considerados os dados das 38 UEs previstos no Censo de 2015, pois a Univesp ainda não possui um histórico de dados no Censo.

${ }^{2}$ Considerou-se, na legislação consultada, o ano em que a IES foi criada (ou autorizada a criação) com a atual denominação de Universidade Estadual. 


\begin{tabular}{|c|c|c|}
\hline & $\begin{array}{l}\text { Universidade Est. Paulista Júlio de Mesquita Filho - Unesp } \\
\text { Universidade Estadual de Campinas - Unicamp }\end{array}$ & $\begin{array}{l}1976 \\
1966 \\
\end{array}$ \\
\hline \multicolumn{3}{|c|}{ Sul } \\
\hline PR & $\begin{array}{l}\text { Universidade Estadual de Londrina - UEL } \\
\text { Universidade Estadual de Maringá - UEM } \\
\text { Universidade Estadual do Norte do Paraná - Uenp } \\
\text { Universidade Estadual de Ponta Grossa - UEPG } \\
\text { Universidade Est. do Centro Oeste do Paraná - Unicentro } \\
\text { Universidade Estadual do Oeste do Paraná - Unioeste } \\
\text { Universidade Estadual do Paraná - Unespar }\end{array}$ & $\begin{array}{l}1969 \\
1969 \\
2006 \\
1969 \\
1997 \\
1994 \\
2001 \\
\end{array}$ \\
\hline $\mathrm{SC}$ & Universidade do Estado de Santa Catarina - Udesc & 1965 \\
\hline $\mathrm{RS}$ & Universidade Estadual do Rio Grande do Sul - Uergs & 2001 \\
\hline \multicolumn{3}{|c|}{ Centro-Oeste } \\
\hline MS & Universidade Estadual de Mato Grosso do Sul - Uems & 1993 \\
\hline MT & Universidade Estadual de Mato Grosso - Unemat & 1993 \\
\hline GO & Universidade Estadual de Goiás - UEG & 1999 \\
\hline
\end{tabular}

Fonte: Sítios eletrônicos das UEs. Documentos institucionais das UEs. Levantamento realizado em 20/06/201

\section{A classificação das UEs brasileiras, segundo os critérios de Steiner (2006)}

Steiner (2006), com o objetivo de subsidiar estudos acadêmicos que visem compreender a desigualdade e as diferentes missões institucionais das universidades no Brasil, propôs, inspirado no sistema de classificação do Instituto de Carnegie, criado em 1971, nos Estados Unidos, "uma classificação tridimensional para as instituições de ensino superior no Brasil com o intuito acadêmico de melhor compreender a diversidade institucional e a complexidade desse universo" (Ibid., p. 328). Esse autor reitera que o objetivo dessa metodologia não é ser um instrumento de ranqueamento dessas instituições, mas sim de oferecer a possibilidade de dimensionar os distintos perfis de atuação acadêmica dessas IES no país. “Assim como no caso de Carnegie, insistimos que a classificação das instituições não deve estar associada à ideia de uma hierarquia institucional, mas sim à intenção de agrupar instituições com missão assemelhada" (Ibid., p. 330).

A proposta de classificação de Steiner (2006, p. 330), inspirada na classificação institucional de Carnegie, é baseada em três dimensões:

Primeira dimensão: nível de formação máxima

Dr - Pesquisa e Doutorado

Ms - Mestrado

Gr - Graduação

Segunda dimensão: diversidade e número de concluintes

Div - Diversificadas - Grande diversidade de programas e grande número de concluintes

Int - Intermediárias - Média diversidade de programas e médio número de concluintes 
Res - Restritas - Pequena diversidade de programas e pequeno número de concluintes

Esp - Instituições especializadas, que fornecem diploma em um único campo do conhecimento

\section{Terceira dimensão: Natureza administrativa}

Pub - Públicas (Federais, Estaduais ou Municipais)

$\mathrm{CCF}$ - Comunitárias, Confessionais e Filantrópicas

Part - Particulares. (Grifo dos autores)

Esse autor esclarece que a primeira e a terceira dimensão são idênticas à classificação de Carnegie e que a segunda foi adaptada, pois o modelo original possui apenas duas categorias. Para os objetivos deste estudo, nos reportaremos somente às duas primeiras dimensões, uma vez que nosso objeto de análise são as UEs e todas são públicas. As categorias das dimensões estabelecidas por essa metodologia de classificação possuem as seguintes definições:

Universidades de pesquisa e doutorado: oferecem tipicamente uma ampla gama de programas de bacharelado e estão comprometidas com o ensino de pós-graduação até o doutorado.

- Universidades de Pesquisa e Doutorado Diversificadas (DrDiv), que oferecem pelo menos 25 programas de doutorado em pelo menos seis grandes áreas do conhecimento e formam pelo menos 150 doutores/ano no período considerado.

- Universidades de Pesquisa e Doutorado Intermediárias (DrInt), que oferecem pelo menos dez programas de doutorado em pelo menos duas grandes áreas do conhecimento e formam pelo menos 50 doutores/ano no período considerado.

- Universidades de Pesquisa e Doutorado Restritas (DrRes), que formaram pelo menos dez doutores/ano em pelo menos três programas ou formaram pelo menos vinte doutores/ano no total.

- Instituições de Pesquisa e de Doutorado Especializadas (DrEsp), que oferecem programas de doutorado, mas oferecem programas de graduação em uma única área do conhecimento ou não oferecem graduação e formaram pelo menos vinte doutores/ano no período considerado.

Universidades de mestrado: oferecem tipicamente uma ampla gama de programas de bacharelado e estão comprometidas com o ensino de pósgraduação até o mestrado.

- Universidade de Mestrado Diversificadas (MsDiv), que oferecem pelo menos cinco programas de mestrado e formaram pelo menos 75 mestres/ano no período considerado.

- Universidades de Mestrado Intermediárias (MsInt), que oferecem pelo menos três programas de mestrado e formaram pelo menos quarenta mestres/ano no período considerado.

- Universidades de Mestrado Restritas (MsRes), que formaram pelo menos vinte mestres/ano no período considerado.

- Instituições Especializadas (MsEsp), que oferecem programas de mestrado, mas oferecem diplomas em um único campo do conhecimento. Formaram pelo menos vinte mestres/ano no período considerado.

Instituições de graduação - Oferecem ensino de graduação.

- Instituições de Graduação Diversificadas (GrDiv), instituições com mais de mil concluintes por ano em pelo menos vinte cursos. 
- Instituições de Graduação Intermediárias (GrInt), instituições com um número anual mínimo de concluintes de quinhentos em pelo menos dez cursos.

- Instituições de Graduação Restritas (GrRes), instituições com menos de quinhentos concluintes por ano.

- Instituições de Graduação Especializadas (GrEsp), instituições que oferecem diploma em um único campo do conhecimento (Tecnológicas, Licenciaturaformação de professores, Profissionais Liberais, Belas Artes). (STEINER, 2006, p. 331-332. Grifo dos autores)

Considerando-se as dimensões e suas definições supramencionadas, Steiner (2006) classificou todas as universidades do país tendo como referência para a apreciação dos dados, o ano de 2003. No quadro 2, estão relacionadas as UEs e as suas respectivas dimensões e categorias, conforme essa metodologia, tendo como referência os anos de 2003, 2007 e 2016. As informações referentes à classificação do ano de 2003 foram extraídas do estudo de Steiner (2006), as de 2007 do estudo de Nunes, Carvalho e Albrecht (2009), que atualizaram essa classificação, e a de 2016 foi realizada por este estudo, ancorada nos critérios e definições já mencionados e subsidiados pelos dados da Capes e do Inep.

De acordo com as informações do quadro 2, no ano de 2003, das 25 UEs que foram analisadas pelo estudo de Steiner (2006), sete classificavam-se como de pesquisa e doutorado, sendo a USP, a Unicamp e a Unesp como universidades de pesquisa e doutorado diversificadas; a Uerj como a única universidade de pesquisa e doutorado intermediária; a UEM, Uenf e UEL como universidades de pesquisa e doutorado restrita. Quanto à categorização de universidade de mestrado, a Funece (Uece) obteve a qualificação de universidade de mestrado diversificada e a Udesc, a Uesc e a Unioeste de universidade de mestrado restrita. É importante perceber que 18 UEs, no ano de 2003, caracterizavam-se como instituições de graduação, sendo oito diversificadas, a UEG, Uema, UPE, Unimontes, UEPG, Uern, UEPB e Unicentro; cinco intermediárias, a Urca, Uneb, UEFS, Uesb e UVA; duas de graduação restrita, a UEMG e a Unitins; três de graduação especializada em cursos de licenciatura, a Uepa, Uems e Unemat.

Quadro 2 - Classificação das universidades estaduais, segundo a metodologia de Steiner

(2006), nos anos de 2003, 2007 e 2016

\begin{tabular}{|c|c|c|c|c|c|c|}
\hline $\begin{array}{l}\text { Dimensões e } \\
\text { categorias }\end{array}$ & Ano de $2003 *$ & $\begin{array}{l}\text { Tot } \\
\text { al }\end{array}$ & $\begin{array}{l}\text { Ano de } \\
2007 * *\end{array}$ & $\begin{array}{l}\text { Tot } \\
\text { al }\end{array}$ & Ano de 2016 & Total \\
\hline $\begin{array}{c}\text { Universidade } \\
\text { s de Pesquisa } \\
\text { e Doutorado } \\
\text { Diversificada } \\
\text { s (DrDiv) }\end{array}$ & $\begin{array}{c}\text { USP } \\
\text { Unicamp } \\
\text { Unesp }\end{array}$ & 03 & $\begin{array}{c}\text { USP } \\
\text { Unicamp } \\
\text { Unesp }\end{array}$ & 03 & $\begin{array}{c}\text { USP } \\
\text { Unicamp } \\
\text { Unesp } \\
\text { Uerj } \\
\text { UEM }\end{array}$ & 05 \\
\hline
\end{tabular}




\begin{tabular}{|c|c|c|c|c|c|c|}
\hline $\begin{array}{l}\text { Universidade } \\
\text { s de Pesquisa } \\
\text { e Doutorado } \\
\text { Intermediária } \\
\text { s (DrInt) }\end{array}$ & Uerj & 01 & $\begin{array}{l}\text { Uerj } \\
\text { UEM }\end{array}$ & 02 & $\begin{array}{c}\text { Uenf } \\
\text { UEL } \\
\text { Unioeste } \\
\text { Udesc }\end{array}$ & 04 \\
\hline $\begin{array}{c}\text { Universidade } \\
\text { s de Pesquisa } \\
\text { e Doutorado } \\
\text { Restritas } \\
\text { (DrRes) }\end{array}$ & $\begin{array}{l}\text { UEM } \\
\text { Uenf } \\
\text { UEL }\end{array}$ & 03 & $\begin{array}{l}\text { UEL } \\
\text { Uenf }\end{array}$ & 02 & $\begin{array}{c}\text { UEFS } \\
\text { Uesc } \\
\text { Uesb } \\
\text { UPE } \\
\text { Uece } \\
\text { UEA } \\
\text { Unimontes } \\
\text { UEPG }\end{array}$ & 08 \\
\hline $\begin{array}{c}\text { Universidade } \\
\text { s de Mestrado } \\
\text { Diversificada } \\
\text { s (MsDiv) }\end{array}$ & $\begin{array}{l}\text { Funece } \\
\text { (Uece) }\end{array}$ & 01 & $\begin{array}{c}\text { Funece } \\
\text { (Uece) } \\
\text { Udesc } \\
\text { Unioeste } \\
\text { Uesc } \\
\text { Uneb }\end{array}$ & 05 & $\begin{array}{c}\text { UEG } \\
\text { Unemat } \\
\text { Uems } \\
\text { UEPB } \\
\text { Uneb } \\
\text { Uema } \\
\text { Uern } \\
\text { Uepa } \\
\text { Unicentro }\end{array}$ & 09 \\
\hline $\begin{array}{c}\text { Universidade } \\
\text { s de Mestrado } \\
\text { Intermediária } \\
\text { s (MsInt) }\end{array}$ & - & - & $\begin{array}{c}\text { UEPG } \\
\text { UEFS } \\
\text { Fundação - } \\
\text { UPE } \\
\end{array}$ & 03 & Uenp & 01 \\
\hline $\begin{array}{l}\text { Universidade } \\
\text { s de Mestrado } \\
\text { Restritas } \\
\text { (MsRes) }\end{array}$ & $\begin{array}{c}\text { Udesc } \\
\text { Unioeste } \\
\text { Udesc }\end{array}$ & 03 & $\begin{array}{l}\text { Uesb } \\
\text { UEA }\end{array}$ & 02 & $\begin{array}{c}\text { Uespi } \\
\text { Urca } \\
\text { UERR } \\
\text { UEMG }\end{array}$ & 04 \\
\hline \multirow{2}{*}{$\begin{array}{c}\text { Instituições } \\
\text { de Graduação } \\
\text { Diversificada } \\
\text { s (GrDiv) }\end{array}$} & $\begin{array}{c}\text { UEG } \\
\text { Uema } \\
\text { UPE } \\
\text { Unimontes }\end{array}$ & \multirow{2}{*}{08} & $\begin{array}{c}\text { Instituições } \\
\text { de } \\
\text { Graduação** } \\
*\end{array}$ & \multirow{4}{*}{18} & $\begin{array}{l}\text { Instituições de } \\
\text { Graduaçãô**** }\end{array}$ & \multirow{4}{*}{07} \\
\hline & $\begin{array}{c}\text { UEPG } \\
\text { Uern } \\
\text { UEPB } \\
\text { Unicentro }\end{array}$ & & \multirow{3}{*}{$\begin{array}{c}\text { Unimontes } \\
\text { Uepa } \\
\text { Uema } \\
\text { Uern } \\
\text { Unemat } \\
\text { UEG } \\
\text { Uems } \\
\text { UEPB } \\
\text { UVA } \\
\text { Urca } \\
\text { UEMG } \\
\text { Unicentro } \\
\text { Uneal }\end{array}$} & & \multirow{3}{*}{$\begin{array}{c}\text { UVA } \\
\text { Uneal } \\
\text { Uncisal } \\
\text { Unitins } \\
\text { Ueap } \\
\text { Unespar } \\
\text { Uergs }\end{array}$} & \\
\hline $\begin{array}{c}\text { Instituições } \\
\text { de Graduação } \\
\text { Intermediária } \\
\text { s (GrInt) }\end{array}$ & $\begin{array}{l}\text { Urca } \\
\text { Uneb } \\
\text { UEFS } \\
\text { Uesb } \\
\text { UVA }\end{array}$ & 05 & & & & \\
\hline $\begin{array}{c}\text { Instituições } \\
\text { de Graduação } \\
\text { Restritas } \\
\text { (GrRes) }\end{array}$ & $\begin{array}{l}\text { UEMG } \\
\text { Unitins }\end{array}$ & 02 & & & & \\
\hline
\end{tabular}




\begin{tabular}{|c|c|c|c|c|c|}
\hline $\begin{array}{c}\text { Instituições } \\
\text { de Graduação } \\
\text { Especializada } \\
\text { s de } \\
\text { Licenciatura }^{3} \\
\text { (GrEsp) }\end{array}$ & $\begin{array}{c}\text { Uepa } \\
\text { Uems } \\
\text { Unemat }\end{array}$ & 03 & $\begin{array}{l}\text { Uncisal } \\
\text { Uespi } \\
\text { Unitins } \\
\text { Uergs } \\
\text { UERR }\end{array}$ & & \\
\hline Total & & $29^{4}$ & & $35^{5}$ & $38^{6}$ \\
\hline
\end{tabular}

Fonte: Steiner (2006). Geocapes, com acesso em: 17 ago. 2017. Elaborado e sistematizado pela autora. *Elaborado por Steiner (2006) e sistematizado pela autora.

** Elaborado por Nunes, Carvalho e Albrecht (2009) e sistematizado pela autora.

*** Nunes, Carvalho e Albrecht (2009) não classificaram por subcategoria as Instituições de Graduação.

**** Assim como Nunes, Carvalho e Albrecht (2009), este estudo não estabeleceu classificação por subcategoria nas Instituições de Graduação.

A classificação realizada por Nunes, Carvalho e Albrecht (2009), tendo como referência o ano de 2007, mostrou que entre 2003 e 2007, ocorreram alterações quanto à classificação das UEs, segundo a metodologia utilizada por Steiner (2006). As três UEs paulistas (USP, Unesp e Unicamp) continuaram sendo as únicas classificadas como de pesquisa e doutorado diversificadas; a UEM passou a configurar, juntamente com a Uerj, como universidades de pesquisa e doutorado intermediárias; a UEL passou para a categoria de universidade de pesquisa e doutorado restrita, assim como a Uenf, que se manteve nessa classificação; ou seja, continuaram sendo sete as UEs classificadas como universidades de pesquisa, o que ocorreu foi somente alteração quanto à dimensão.

No que diz respeito às UEs classificadas como universidades de mestrado, os dados de 2007 indicaram que dez delas obtiveram a caracterização de universidade de mestrado, sendo cinco de universidade de mestrado diversificada, a Funece (Uece), a Udesc, a Unioeste, a Uesc, e a Uneb; três como universidade de mestrado intermediária, a UEPG, a UEFS e a UPE; e duas como universidade de mestrado restrita, a Uesb e a UEA. Das 35 UEs que foram analisadas no estudo de Nunes, Carvalho e Albrecht (2009), 18 receberam a classificação de instituições de ensino, a Unimontes, a Uepa, a Uema, a Uern, a Unemat, a UEG, a Uems, a UEPB, a UVA, a Urca, a UEMG, a Unicentro, a Uneal, a Uncisal, a Uespi, a Unitins, a Uergs e a UERR.

\footnotetext{
${ }^{3}$ Segundo Steiner (2006), as Instituições de Licenciatura possuem apenas cursos de licenciatura plena ou possuem um número de cursos de licenciatura ao menos três vezes maior do que o número de cursos de bacharelado.

${ }^{4}$ Embora já tivessem sido legalmente criadas, a Uespi, a Uneal, a UEA, a Unespar e a Uergs não foram contempladas no levantamento da pesquisa de Steiner (2006).

${ }^{5}$ Embora já tivessem sido legalmente criadas, a Ueap, a Uenp e a Unespar não foram contempladas no levantamento da pesquisa de Nunes, Carvalho e Albrecht (2009).

${ }^{6}$ Como este estudo não obteve acesso às informações institucionais da Univesp, em virtude disso ela não fez parte das classificações realizadas neste subitem.
} 
A reavaliação das UEs realizada por este estudo, segundo os critérios de classificação institucional de Steiner (2006), apresentou consideráveis alterações quanto aos resultados obtidos referentes aos anos de 2003 e 2007. No ano de 2016, das 38 UEs, 17 alcançaram a classificação de universidade de pesquisa e doutorado. Além da USP, Unicamp e Unesp, a Uerj e a UEM também alcançaram o patamar de universidade de pesquisa e doutorado diversificada; a Uenf, a UEL, a Unioeste e a Udesc se elevaram à condição de universidade de pesquisa e doutorado intermediária; e, como universidade de pesquisa e doutorado restrita, foram caracterizadas as seguintes UEs: UEFS, Uesc, Uesb, UPE, Uece, UEA, Unimontes e UEPG.

Das 14 UEs que obtiveram a classificação de universidade de mestrado, nove foram de mestrado diversificadas, a UEG, Unemat, Uems, UEPB, Uneb, Uema, Uern, Uepa e Unicentro; uma de universidade de mestrado intermediária, a Uenp; e quatro como de mestrado restrita, a Uespi, a Urca, a UERR e a UEMG. Diferentemente dos anos de 2003 e 2007, em que 18 UEs foram classificadas como instituições de graduação, no ano de 2016 foram sete as UEs classificadas como instituição de graduação, a UVA, Uneal, Uncisal, Unitins, Ueap, Unespar e Uergs. Cabe ressaltar que há UEs que apresentaram indicadores muito próximos ao estabelecido pela dimensão e/ou categoria seguinte à sua, ou seja, estão em fase de transição para uma nova dimensão/categoria.

Dentre estas sete UEs que obtiveram a classificação de instituição de graduação, somente a UVA foi criada antes da CF de 1988, no ano de 1984. A Uneal e a Unitins foram criadas em 1995 e 1996, respectivamente. A Unespar, a Uergs, a Uncisal e a Ueap foram criadas após a LDB/1996, sendo as duas primeiras no ano de 2001 e as outras duas em 2005 e 2006, respectivamente, ou seja, fazem parte do rol das mais jovens UEs do país, considerando-se o ano de criação.

As análises indicam que, nos anos de 2003 e de 2007, apenas sete UEs possuíam a classificação de Universidades de pesquisa e doutorado. No ano de 2016, das 38 UEs existentes, 17 foram consideradas como Universidades de pesquisa e doutorado, ou seja, melhoraram a qualificação do corpo docente e elevaram, consideravelmente, a sua atuação e diversificação no campo da pesquisa e da pós-graduação stricto sensu.

\section{As UEs segundo a classificação com base no número de cursos de doutorado com conceito} 5 ou mais, segundo metodologia proposta por Nunes, Carvalho e Albrecht (2009) 
Nunes, Carvalho e Albrecht (2009) desenvolveram um estudo intitulado de "Quantas universidades realmente existem no Brasil?", composto por três partes/volumes, cujo objetivo principal foi compreender as diferenças existentes no conjunto das IES brasileiras reconhecidas como universidade. Esses autores questionam essa acentuada diferença existente no conjunto dessas instituições e também a omissão do poder dos processos regulatórios quanto ao que é exigido pela legislação normativa e regulatória.

$\mathrm{Na}$ tentativa de melhor compreender a diversidade institucional existente entre as universidades do país, esses autores realizaram um denso levantamento acerca dos dados institucionais dessas IES e também de modelos classificatórios que permitissem compará-las. Nunes, Carvalho e Albrecht (2009) ressaltam que o estudo não possuía o objetivo de hierarquizar essas instituições, mas sim compreendê-las segundo especificidades acadêmicas. “Um sistema classificatório simplesmente separa as instituições em categorias comparáveis, não determina quais são melhores ou piores.” (Ibid., p.10).

Esses autores defendiam que a classificação de universidades não deveria ocorrer somente pelo critério de existência ou não de cursos de mestrado ou doutorado, sendo necessário considerar também o estágio desses cursos, uma vez que

[...] analisar apenas o número de cursos de mestrado e doutorado não nos mostra uma realidade coerente. Ignora, por exemplo, a maturidade das instituições, a variedade de cursos oferecidos pelas universidades, bem como a qualidade do ensino de graduação. Se, entende-se que as universidades devem possuir programas de pesquisa consolidados e de excelência; uma boa forma de medirmos e apreendermos a realidade brasileira é através da análise dos programas de pós-graduação stricto sensu das universidades. (Ibid., p. 20)

Nessa perspectiva, esses autores, além de realizarem a atualização com base nos dados do ano de 2008, da classificação realizada por Steiner (2006) referente ao ano de 2003, e de analisarem as universidades brasileiras pelos critérios regulatórios, também estabeleceram outros modelos de classificação dessas instituições que contemplavam a existência de cursos de doutorado com notas da Capes superiores a 5, a existência de cursos de doutorado com conceito Capes 6 ou 7 e também com base na diversidade de cursos de doutorado por área do conhecimento. Neste estudo, será utilizado o primeiro modelo proposto para a apreciação das 38 UEs.

A classificação institucional das universidades, de acordo com o número de cursos de doutorado com nota igual ou superior a cinco, apresenta três classificações com duas subcategorias cada e possui os seguintes critérios: 
As Universidades com pelo menos 40 cursos de doutorado com conceito 5 ou mais foram consideradas: "Universidades com pesquisa institucionalizada A", de 19 até 39 cursos de doutorado com conceito igual ou acima de 5 ficaram como "Universidades de pesquisa institucionalizada B". Uma segunda categoria criada foi a de "Universidades em processo de institucionalização" que são aquelas com até 18 cursos de doutorado com conceitos iguais ou acima de 5 e as que ofertam cursos de doutorado, mas que apresentam conceitos abaixo de 5. A terceira categoria é a de "Universidades sem pesquisa institucionalizada" que corresponde às Universidades sem doutorado, mas com mestrado ou as sem doutorado e mestrado. (NUNES; CARVALHO; ALBRECHT, 2009, p. 36-37. Grifo dos autores)

Tendo em vista os critérios estabelecidos por essa classificação, os dados do quadro 3 apresentam como as UEs foram classificadas segundo essa metodologia de análise. Os dados referentes ao ano de 2008 foram extraídos do estudo de Nunes, Carvalho e Albrecht (2009) e os de 2016 foram elaborados por este estudo. No ano de 2008, havia três UEs que alcançaram a classificação de universidade com pesquisa institucionalizada tipo A: a USP, a Unesp e a Unicamp. Das 35 UEs analisadas nesse ano, 14 foram classificadas como universidade em processo de institucionalização, sendo seis delas no tipo A: a Uerj, a UEM, a UEL, a Uece, a Uenf e a UEFS; e oito no tipo B: a Udesc, a UEPG, a Unioeste, a UPE, a Uneb, a Uesc, a Uesb e a UEA.

No que diz respeito às UEs classificadas como sem pesquisa institucionalizada, as de tipo A são as sem doutorado, mas que possuem mestrado. Nessa categoria, existiam 12 UEs no ano de 2008: a UEPB, a Unimontes, a Unicentro, a Uern, a Unemat, a UEG, a Uema, a UEMG, a Uems, a UVA, a Urca e a Uepa. As de tipo B são as sem doutorado e sem mestrado e somavam seis UEs: a Uneal, a Uncisal, a Uespi, a Unitins, a Uergs e a UERR.

Quadro 3 - UEs com pesquisa institucionalizada, em processo de institucionalização e sem pesquisa institucionalizada, pelo critério de número de cursos de doutorado com conceito 5, 6 ou 7

\begin{tabular}{|c|c|c|c|c|c|c|}
\hline Classificação & Tipo & Critérios & 2008* & Total & 2016 & Total \\
\hline \multirow{2}{*}{ 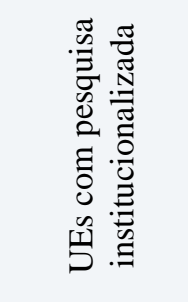 } & A & $\begin{array}{c}\text { Com pelo menos } 40 \\
\text { cursos de doutorado } \\
\text { com conceito } 5,6 \text { ou } \\
7\end{array}$ & $\begin{array}{c}\text { USP } \\
\text { Unesp } \\
\text { Unicamp }\end{array}$ & 03 & $\begin{array}{l}\text { USP } \\
\text { Unesp } \\
\text { Unicamp }\end{array}$ & 03 \\
\hline & B & $\begin{array}{c}\text { De } 19 \text { a } 39 \text { cursos de } \\
\text { doutorado com } \\
\text { conceito } 5,6 \text { ou } 7\end{array}$ & - & 00 & Uerj & 01 \\
\hline
\end{tabular}




\begin{tabular}{|c|c|c|c|c|c|c|c|}
\hline 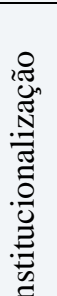 & A & $\begin{array}{l}\text { Até } 18 \text { cursos de } \\
\text { doutorado com } \\
\text { conceito } 5,6 \text { ou } 7\end{array}$ & $\begin{array}{c}\text { Uerj } \\
\text { UEM } \\
\text { UEL } \\
\text { Uece } \\
\text { Uenf } \\
\text { UEFS }\end{array}$ & 06 & $\begin{array}{l}\text { UEFS } \\
\text { Uesc } \\
\text { Uesb } \\
\text { Uece } \\
\text { UEA } \\
\text { Uenf } \\
\text { Uneb } \\
\end{array}$ & $\begin{array}{c}\text { Unimontes } \\
\text { UEL } \\
\text { UEM } \\
\text { UEPG } \\
\text { Unioeste } \\
\text { Udesc } \\
\text { UEMG } \\
\end{array}$ & 14 \\
\hline $\begin{array}{l}0 \\
0 \\
0 \\
0 \\
0 \\
0 \\
0 \\
\vdots \\
0 \\
\Xi \\
0 \\
n \\
\vdots \\
\vdots\end{array}$ & B & $\begin{array}{l}\text { Com curso de } \\
\text { doutorado com } \\
\text { conceito } 3 \text { ou } 4\end{array}$ & $\begin{array}{c}\text { Udesc } \\
\text { UEPG } \\
\text { Unioeste } \\
\text { UPE } \\
\text { Uneb } \\
\text { Uesc } \\
\text { Uesb } \\
\text { UEA }\end{array}$ & 08 & $\begin{array}{l}\text { Uems } \\
\text { UPE } \\
\text { UEG } \\
\text { UEPB } \\
\text { Uema }\end{array}$ & $\begin{array}{c}\text { Unemat } \\
\text { Uern } \\
\text { Uepa } \\
\text { Uenp } \\
\text { Unicentro }\end{array}$ & 10 \\
\hline \multirow{2}{*}{ 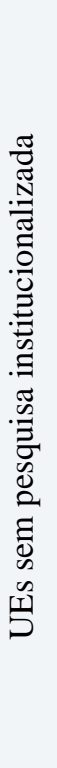 } & A & $\begin{array}{l}\text { Sem doutorado, com } \\
\text { mestrado }\end{array}$ & $\begin{array}{c}\text { UEPB } \\
\text { Unimontes } \\
\text { Unicentro } \\
\text { Uern } \\
\text { Unemat } \\
\text { UEG } \\
\text { Uema } \\
\text { UEMG } \\
\text { Uems } \\
\text { UVA } \\
\text { Urca } \\
\text { Uepa }\end{array}$ & 12 & & $\begin{array}{c}\text { Uespi } \\
\text { Urca } \\
\text { UVA } \\
\text { Uneal } \\
\text { UERR } \\
\text { Unespar } \\
\text { Uergs }\end{array}$ & 07 \\
\hline & B & $\begin{array}{l}\text { Sem doutorado e sem } \\
\text { mestrado }\end{array}$ & $\begin{array}{l}\text { Uneal } \\
\text { Uncisal } \\
\text { Uespi } \\
\text { Unitins } \\
\text { Uergs } \\
\text { UERR }\end{array}$ & 06 & & $\begin{array}{l}\text { Uncisal } \\
\text { Unitins } \\
\text { Ueap }\end{array}$ & 03 \\
\hline Total & & & & 35 & & & 38 \\
\hline
\end{tabular}

Fonte: Nunes, Carvalho e Albrecht (2009). Capes - Avaliação quadrienal (2014 a 2017). Elaborado e sistematizado pela autora.

* Elaborado por Nunes, Carvalho e Albrecht (2009) e sistematizado pela autora.

Seguindo os mesmos critérios de análise, no ano de 2016 as três UEs paulistas continuaram sendo as únicas do conjunto das universidades estaduais do país a obterem a classificação de universidade com pesquisa institucionalizada tipo A e a Uerj logrou a do tipo B. No ano de 2008, foram 14 UEs classificadas como universidade em processo de institucionalização, sendo seis de tipo A e oito de tipo B. No ano de 2016, foram 24 as UEs que obtiveram essa classificação, sendo 14 de tipo A: a UEFS, a Uesc, a Uesb, a Uece, a UEA, a Uenf, a Uneb, a Unimontes, a UEL, a UEM, a UEPG, a Unioeste, a Udesc e a UEMG. Tendo em vista a nova classificação realizada por este estudo, foram 10 as UEs categorizadas como 
universidade em processo de institucionalização de tipo B: a Uems, a UPE, a UEG, a UEPB, a Uema, a Unemat, a Uern, a Uepa, a Uenp e a Unicentro.

Diferentemente do ano de 2008 em que 18 UEs foram classificadas como universidades sem pesquisa institucionalizada, no ano de 2016 foram 10, sendo sete sem doutorado e com mestrado: a Uespi, a Urca, a UVA, a Uneal, a UERR, a Unespar e a Uergs; e três as UEs como sem doutorado e sem mestrado: a Uncisal, a Unitins e a Ueap.

Assim como identificado na metodologia proposta por Steiner (2006), no modelo classificatório proposto por Nunes, Carvalho e Albrecht (2009), o conjunto das UEs também apresentou elevação em suas classificações, especialmente quanto à elevação de instituições que lograram a característica de universidades em processo de institucionalização. Essa evolução foi alcançada devido a melhorias nas características acadêmicas dessas UEs, em especial quanto à titulação do corpo docente e ao aprimoramento das atividades no campo da pesquisa e da pós-graduação.

É preciso ressaltar que, das 10 UEs consideradas como sem pesquisa institucionalizada, três foram criadas entre 1988 e 1996: a Uespi, em 1988; a Uneal, em 1995; e a Unitins; em 1996; e cinco UEs criadas no intervalo de 1997 a 2016: a Unespar, a Uergs, a UERR, a Uncisal e a Ueap. Dessas 10 UEs, sete também foram classificadas como instituições de graduação no levantamento realizado por este estudo, tendo como base o modelo proposto por Steiner (2006): a UVA, a Uneal, a Uncisal, a Unitins, a Ueap, a Unespar e a Uergs.

\section{As UEs e os critérios normativos e regulatórios da Resolução n. ${ }^{\circ}$ 03/2010 do CNE}

A LDB/1996 definiu que as universidades "são instituições pluridisciplinares de formação dos quadros profissionais de nível superior, de pesquisa, de extensão e de domínio e cultivo do saber humano" (art. 52). Dispôs também que elas são caracterizadas pela produção intelectual institucionalizada por meio do estudo sistemático dos temas e problemas mais relevantes, tanto do ponto de vista científico e cultural quanto regional e nacional, pela existência de um terço do corpo docente com titulação acadêmica de mestrado ou doutorado, e igual proporção em regime de tempo integral.

No intuito de melhor elucidar o conteúdo do referido artigo da LDB/1996, o CNE (2007) reitera que essa legislação procurou qualificar as universidades do país por meio de critérios qualitativos e quantitativos, uma vez que 
[...] a forma qualitativa de caracterização foi disposta nos termos do caput e do inciso I (pesquisa intelectual institucionalizada). A opção quantitativa manifesta-se na associação do cumprimento de suas funções de ensino, pesquisa e extensão ao atendimento a percentuais mínimos de titulação e de regime de trabalho do corpo docente. (CNE, 2007, p. 3)

Além de ressaltar esse binômio existente na caracterização institucional dessas IEs, o CNE (2007) também ressaltou a assimetria desse conjunto de instituições no país. Em Parecer que aborda a caracterização dessas instituições, os relatores desse documento por entenderem

[...] ser complexa e diversificada a realidade institucional das universidades brasileiras, apresentaram orientações para avaliação e supervisão do atendimento dessas instituições ao disposto no art. 52 da LDB. Por também entenderem que o referido artigo deva ser considerado pelo conjunto de seus dispositivos, bem como pelos fins que almeja, e não apenas pelos objetos dispostos no caput ou por um dos seus incisos isoladamente, sugeriram critérios quantitativos, como também orientação em base qualitativa. Nesse sentido, essas orientações visam a realçar a necessária diversidade institucional que caracteriza as universidades brasileiras, mas também possibilitar que cada uma delas, em conformidade com a sua missão e natureza institucional, ajuste a composição de seu corpo docente às disposições legais. (CNE, 2007, p. 27)

Nessa perspectiva de compreensão, a Resolução n..$^{\circ} 03$ do CNE, que regulamenta o art. 52 da LDB/1996 e dispõe sobre normas e procedimentos para credenciamento e recredenciamento de universidades do Sistema Federal de Educação Superior, estabelece os critérios mínimos para que uma IES desse sistema seja considerada universidade. As UEs não compõem o rol das instituições do Sistema Federal por estarem subordinadas aos seus respectivos estados. Como cada estado possui a prerrogativa para a realização dos processos regulatórios e normativos de suas IES, este estudo utilizará parte dos critérios dessa Resolução do CNE como parâmetro mínimo para analisar se as UEs atendem ou não a esses requisitos, uma vez que essa Resolução trata com densidade a discussão sobre as características institucionais e acadêmicas para que uma IES seja considerada como universidade.

Carvalho (2013), em seu estudo sobre a UEG, utilizou a Resolução n. ${ }^{\circ} 03$ do CNE e a Resolução n. ${ }^{\circ} 02$ do Conselho Estadual de Educação de Goiás como um dos parâmetros para analisar se a UEG possuía as condições legais e normativas mínimas para ser uma universidade. Os resultados dessa avaliação indicaram que essa instituição não atendia aos requisitos mínimos previstos nesses dois documentos normativos e, mesmo não atendendo, ela era credenciada como universidade.

Segundo a Resolução n. ${ }^{\circ} 03$ do CNE, de 14 de outubro de 2010: 
Art. $3^{\circ}$ São condições prévias indispensáveis para o requerimento de credenciamento como universidade:

I - um terço do corpo docente, com titulação de mestrado ou doutorado, conforme o inciso II do art. 52 da Lei n. $^{\circ}$ 9.394/1996 e respectivas regulamentações;

II - um terço do corpo docente em regime de tempo integral, conforme o inciso III do art. 52 da Lei n. ${ }^{\circ}$ 9.394/1996 e parágrafo único do art. 69 do Decreto n. ${ }^{\circ}$ 5.773/2006;

III - Conceito Institucional (CI) igual ou superior a 4 (quatro) na última Avaliação Institucional Externa do Sistema Nacional de Avaliação da Educação Superior (SINAES);

IV - Índice Geral de Cursos (IGC) igual ou superior a 4 (quatro) na última divulgação oficial do Instituto Nacional de Estudos e Pesquisas Anísio Teixeira (INEP);

V - oferta regular de, no mínimo, 60\% (sessenta por cento) dos cursos de graduação reconhecidos ou em processo de reconhecimento devidamente protocolado, no prazo regular;

VI - oferta regular de, pelo menos, 4 (quatro) cursos de mestrado e 2 (dois) de doutorado, reconhecidos pelo Ministério da Educação (MEC);

VII - compatibilidade do Plano de Desenvolvimento Institucional (PDI) e do Estatuto com a categoria de universidade;

VIII - não ter sofrido, nos últimos 5 (cinco) anos, relativamente à própria instituição ou a qualquer de seus cursos, as penalidades de que trata o $\S 1^{\circ}$ do art. 46 da Lei n. ${ }^{\circ} 9.394 / 1996$, regulamentado pelo art. 52 do Decreto n. ${ }^{\circ}$ 5.773/2006. (BRASIL, 2010, p. 1. Grifo dos autores)

Nessa perspectiva, o quadro 4 apresenta quais são as UEs que atendem, não atendem ou atendem parcialmente aos requisitos previstos nos incisos I, II, IV e VI dessa Resolução. As informações referentes aos demais critérios acima elencados são específicos do processo normativo e regulatório das IES federais e privadas e não são possíveis de serem obtidos para as UEs, uma vez que os processos normativos e regulatórios dessas instituições são realizados por seus estados.

Quadro 4 - Síntese do levantamento dos critérios da Resolução n. ${ }^{\circ}$ 03/2010 do CNE para uma IES ser universidade aplicado para as UEs - ano de 2016

\begin{tabular}{|c|c|c|c|c|c|c|}
\hline & & $\begin{array}{c}\text { I) } 1 / 3 \text { do } \\
\text { corpo } \\
\text { docente ( } \\
\text { mestre e/ou } \\
\text { doutor) }\end{array}$ & $\begin{array}{l}\text { II) } 1 / 3 \text { do } \\
\text { corpo } \\
\text { docente } \\
\text { (tempo } \\
\text { integral) }\end{array}$ & $\begin{array}{c}\text { IV) IGC igual ou } \\
\text { superior a } 4 \text { na } \\
\text { última } \\
\text { divulgação } \\
\text { oficial do Inep }\end{array}$ & $\begin{array}{l}\text { VI) Oferta regular de, } \\
\text { pelo menos, } 4 \text { cursos de } \\
\text { mestrado e } 2 \text { de } \\
\text { doutorado, reconhecidos } \\
\text { pelo MEC }\end{array}$ & Consideração final \\
\hline \multicolumn{7}{|c|}{ Norte } \\
\hline RR & UERR & Atende & Atende & Não atende & Atende parcialmente & Atende parcialmente \\
\hline TO & Unitins & Atende & Atende & Não atende & Não atende & Atende parcialmente \\
\hline AP & Ueap & Atende & Atende & Não atende & Não atende & Atende parcialmente \\
\hline $\mathrm{AM}$ & UEA & Atende & Atende & Não atende & Atende parcialmente & Atende parcialmente \\
\hline PA & Uepa & Atende & Atende & Não atende** & Atende parcialmente & Atende parcialmente \\
\hline \multicolumn{7}{|c|}{ Nordeste } \\
\hline PB & UEPB & Atende & Atende & Não atende & Atende & Atende parcialmente \\
\hline BA & UEFS & Atende & Atende & Não atende & Atende & Atende parcialmente \\
\hline
\end{tabular}




\begin{tabular}{|c|c|c|c|c|c|c|}
\hline & Uesc & Atende & Atende & Atende & Atende & Atende \\
\hline & Uneb & Atende & Atende & Não atende & Atende parcialmente & Atende parcialmente \\
\hline & Uesb & Atende & Atende & Atende & Atende & Atende \\
\hline PI & Uespi & Atende & Atende & Não atende & Não atende & Atende parcialmente \\
\hline MA & Uema & Atende & Atende & Não atende & Atende parcialmente & Atende parcialmente \\
\hline $\mathrm{PE}$ & UPE & Atende & Atende & Não atende & Atende & Atende parcialmente \\
\hline \multirow{3}{*}{$\mathrm{CE}$} & Uece & Atende & Atende & Não atende & Atende & Atende parcialmente \\
\hline & Urca & Atende & Atende & Não atende & Não atende & Atende parcialmente \\
\hline & UVA & Atende & Atende & Não atende & Não atende & Atende parcialmente \\
\hline \multirow{2}{*}{$\mathrm{AL}$} & Uneal & Atende & Atende & Não atende & Não atende & Atende parcialmente \\
\hline & Uncisal & Atende & Atende & Não atende & Não atende & Atende parcialmente \\
\hline $\mathrm{RN}$ & Uern & Atende & Atende & Não atende & Atende parcialmente & Atende parcialmente \\
\hline \multicolumn{7}{|c|}{ Sudeste } \\
\hline \multirow{2}{*}{$\mathrm{RJ}$} & Uerj & Atende & Atende & Atende & Atende & Atende \\
\hline & Uenf & Atende & Atende & Atende & Atende & Atende \\
\hline \multirow{2}{*}{ MG } & UEMG & Atende & Atende & Não atende & Não atende & Atende parcialmente \\
\hline & Unimontes & Atende & Atende & Não atende & Atende & Atende parcialmente \\
\hline \multirow{3}{*}{$\mathrm{SP}$} & USP & Atende & Atende & $* * *$ & Atende & Atende \\
\hline & Unesp & Atende & Atende & Atende & Atende & Atende \\
\hline & Unicamp & Atende & Atende & Atende & Atende & Atende \\
\hline \multicolumn{7}{|c|}{ Sul } \\
\hline \multirow{7}{*}{ PR } & UEL & Atende & Atende & Atende & Atende & Atende \\
\hline & UEM & Atende & Atende & Atende & Atende & Atende \\
\hline & Uenp & Atende & Atende & Não atende & Não atende & Atende parcialmente \\
\hline & UEPG & Atende & Atende & Atende & Atende & Atende \\
\hline & Unicentro & Atende & Atende & Atende & Atende & Atende \\
\hline & Unioeste & Atende & Atende & Atende & Atende & Atende \\
\hline & Unespar & Atende & Atende & Não atende & Não atende & Atende parcialmente \\
\hline $\mathrm{SC}$ & Udesc & Atende & Atende & Atende & Atende & Atende \\
\hline $\mathrm{RS}$ & Uergs & Atende & Atende & Atende & Não atende & Atende parcialmente \\
\hline \multicolumn{7}{|c|}{ Centro-Oeste } \\
\hline MT & Unemat & Atende & Atende & Não atende & Atende & Atende parcialmente \\
\hline MS & Uems & Atende & Atende & Não atende & Atende & Atende parcialmente \\
\hline GO & UEG & Atende & Atende & Não atende & Atende parcialmente & Atende parcialmente \\
\hline
\end{tabular}

Fonte: Inep - Censo da Educação Superior de 2016. Geocapes. Sistematização e classificação realizada por este estudo de acordo com os critérios estabelecidos pela Resolução n. ${ }^{\circ}$ 03/2010 do Conselho Nacional de Educação. * Para os estados que possuem mais de uma UEs, foi considerado o total das funções docentes em universidades estaduais para todas as UEs.

* *Dado referente ao ano de 2013. Nos resultados do IGC/Inep do ano de 2015, não consta a Uepa; já no de 2014 consta sem conceito (SC).

*** Não consta dados da USP no banco de dados do IGC/Inep.

As informações contidas no quadro 4 mostram que, das 38 UEs, apenas 13 atendem aos quatro requisitos previstos na Resolução n. ${ }^{\circ}$ 03/2010 do $\mathrm{CNE}$, sendo duas da região Nordeste: a Uesc e a Uesb; cinco da região Sudeste: a Uerj, Uenf, USP, Unesp e Unicamp; e seis são da região Sul: a UEL, UEM, UEPG, Unicentro, Unioeste e a Udesc. No que diz respeito 
aos requisitos de um terço do corpo docente ser mestres e/ou doutores e essa mesma proporção em regime de tempo integral, todas as UEs atenderam a esses dois critérios.

No que se refere ao item IV do art. $3^{\circ}$ dessa Resolução, que estabelece que o Índice Geral de Cursos (IGC) seja igual ou superior a quatro na última divulgação oficial do Inep, as informações do quadro 4 apontam que treze UEs atenderam a esse requisito: a Uesc, a Uesb, a Uerj, a Uenf, a Unesp, a Unicamp, a UEL, a UEM, a UEPG, a Unicentro, a Unioeste, a Udesc e a Uergs. A USP não constava do banco de dados do Sinaes, que fornece do IGC.

Quanto ao requisito VI, que dispõe sobre a oferta de, no mínimo, quatro cursos de mestrado e dois de doutorado, a análise identificou que 11 UEs ainda não atendiam a essa solicitação, sendo cinco da região Nordeste: a Uespi, Urca, UVA, Uneal e Uncisal; duas da região Norte: a Ueap e a Unitins; três da região Sul: a Uenp, Unespar e Uergs; e uma na região Sudeste: a UEMG. Ainda sobre esse requisito, sete UEs atendiam parcialmente: a UEG, da região Centro-Oeste; a Uneb, Uema e Uern, da região Nordeste; e URR, UEA e Uepa, da região Norte. Essa análise realizada evidenciou que os principais desafios a serem superados pelas UEs, que atendem parcialmente às exigências da Resolução n. ${ }^{\circ}$ 003/2010 do CNE, centram-se no IGC e na oferta incipiente ou inexistente de cursos de pós-graduação stricto sensu.

Considerando os dados obtidos nos quadros 2, 3 e 4, dentre as UEs que não atenderam ao requisito VI da Resolução n. ${ }^{\circ}$ 03/2010 do CNE, destaca-se que a UVA, Uneal, Uncisal, Unitins, Ueap, Unespar e Uergs, além de não atenderem a esse requisito, foram também classificadas como IES sem pesquisa institucionalizada, segundo a metodologia de Nunes, Carvalho e Albrecht (2009), e como instituições de graduação, na abordagem proposta por Steiner (2006); a Uespi, a Urca e a UERR, além de não atenderem a esse requisito, também foram classificadas como IES sem pesquisa institucionalizada, segundo a metodologia de Nunes, Carvalho e Albrecht (2009), e como instituições de mestrado restrita, na abordagem proposta por Steiner (2006).

\section{Considerações finais}

As análises empreendidas quanto à metodologia de classificação institucional, proposta por Steiner (2006) e por Nunes, Carvalho e Albrecht (2009), mostraram que, entre os períodos apreciados, ocorreu uma considerável melhoria dos perfis institucionais das UEs, tendo em vista os critérios adotados. Porém, ainda há UEs que possuem desafios a serem superados quanto a suas atividades de pesquisa e atuação na pós-graduação stricto sensu. A 
análise das características institucionais das UEs, considerando os critérios normativos/regulatórios contidos na Resolução n. ${ }^{\circ}$ 03/2010 do CNE, ratificou a heterogeneidade desse campo no que concerne à oferta de educação superior, em especial quanto às diferenças regionais, uma vez que a maioria das UEs que atenderia a todos os requisitos previstos pela Resolução é da região Sul e Sudeste.

Em relação à análise das características das UEs, segundo critérios de classificação institucional e normativo, foi possível observar a existência de assimetrias entre as UEs do país. Levando-se em consideração os critérios de apreciação propostos por Steiner (2006), no ano de 2016, das 38 UEs, cinco foram consideradas como universidades de pesquisa e doutorado diversificadas e sete foram classificadas como instituições de graduação. Tendo em vista os critérios estabelecidos por Nunes, Carvalho e Albrecht (2009), das 38 UEs, quatro obtiveram a classificação de universidade com pesquisa institucionalizada, sendo três de tipo A e uma de tipo B; dez UEs foram categorizadas como universidades sem pesquisa institucionalizada, sendo sete de tipo A e três de tipo B.

Quando as UEs foram apreciadas considerando os critérios normativos e regulatórios previstos na Resolução n. ${ }^{\circ}$ 03/2010 do CNE, este estudo identificou que apenas 13 delas atenderiam a todos os requisitos previstos nessa resolução para que uma IES pudesse ser considerada uma universidade. Vale destacar ainda que 11 delas são das regiões Sul e Sudeste. É preciso considerar, porém, quanto às análises empreendidas sobre essa categoria analítica que, embora os dados apresentados evidenciem as assimetrias desse conjunto, foi possível apreender também que muitas UEs apresentaram melhorias quanto às suas características acadêmicas.

Embora as UEs integrem a mesma categoria administrativa, sendo "universidades públicas estaduais", elas se constituem por um conjunto de IES marcado por assimetrias institucionais em diversos aspectos: quanto à sua arquitetura de organização espacial; quanto à titulação de seu corpo docente; quanto às suas características e perfil institucional e acadêmico, quanto à oferta e atuação na pós-graduação stricto sensu e etc. Este estudo compreende que essas assimetrias identificadas no conjunto das UEs são decorrentes, principalmente, do fato de elas possuírem contextos muito distintos quanto à sua criação, estruturação e funcionamento, e por estarem subordinadas a mantenedores (estados da federação) e regulamentações acadêmicas e institucionais distintos. Os dados e análises obtidos por meio deste estudo explicitam contradições quanto à oferta de educação superior promovida pelas UEs no país e retratam as desigualdades regionais desse conjunto de IES.. 


\section{REFERÊNCIAS}

BRASIL. Constituição da República Federativa do Brasil: 1988. Diário Oficial da União, Brasília, DF: Senado Federal, 1988.

Lei n. ${ }^{\circ}$ 9.394, de 26 de dezembro de 1996. Estabelece as Diretrizes e Bases da Educação Nacional, Brasília, DF, 1996.

Instituto Nacional de Estudos e Pesquisas Educacionais Anísio Teixeira (Inep).

Sinopse Estatística do Censo da Educação Superior. Brasília, DF: MEC.

Conselho Nacional de Educação (CNE). Resolução n. 03 de 14 de outubro de

2010. Regulamenta o Art. 52 da Lei ${ }^{\circ}$ 9.394, de 20 de dezembro de 1996, e dispõe sobre normas e procedimentos para credenciamento e recredenciamento de universidades do Sistema Federal de Ensino. CNE. Brasília, DF, 2010.

CUNHA, Luiz Antônio. Crise de identidade na universidade pública: a avaliação em questão. Revista Universidade e Sociedade, Brasília, v. 3, p. 1-5, jun.1992.

NUNES, Edson; CARVALHO, Márcia de; ALBRECHT, Júlia Vogel de. Quantas universidades realmente existem no Brasil? (Documento de Trabalho n. 82 - Parte I). Rio de Janeiro: Observatório Universitário, 2009.

STEINER. João E. Diferenciação e classificação das instituições de ensino superior no Brasil. In: STEINER. João E.; MALNIC, Gerhanrd (Orgs.). Ensino Superior: Conceito \& Dinâmica. São Paulo: EDUSP, 2006. p. 327-351.

\section{SOBRE OS AUTORES:}

\section{Renata Ramos da Silva Carvalho}

Doutora em Educação pela UFG, Docente da Universidade Estadual de Goiás - UEG (Câmpus Inhumas); Docente no Programa de Pós-Graduação em Educação da UEG; Integrante da rede Universitas'Br (GT1- Política Econômica e financiamento da educação superior no Brasil). Pesquisadora na área de Políticas Educacionais, gestão e financiamento com ênfase em educação superior e universidades estaduais E-mail: renataramosprof@yahoo.com.br

(iD http://orcid.org/0000-0002-7461-6698

\section{Nelson Cardoso Amaral}

Doutor em Educação pela Unimep; Professor Associado II, aposentado, da UFG; Docente no Programa de Pós-Graduação em Educação da UFG; Integrante da rede Universitas'Br (GT1Política Econômica e financiamento da educação superior no Brasil); Pesquisador na área de políticas educacionais com ênfase financiamento, gestão e avaliação educacional. E-mail: nelsoncardosoamaral@gmail.com

(iD http://orcid.org/0000-0002-3593-9582 